\title{
Bedeutende Neuerwerbungen
}

\section{Der Nachlass von Walter Brudi}

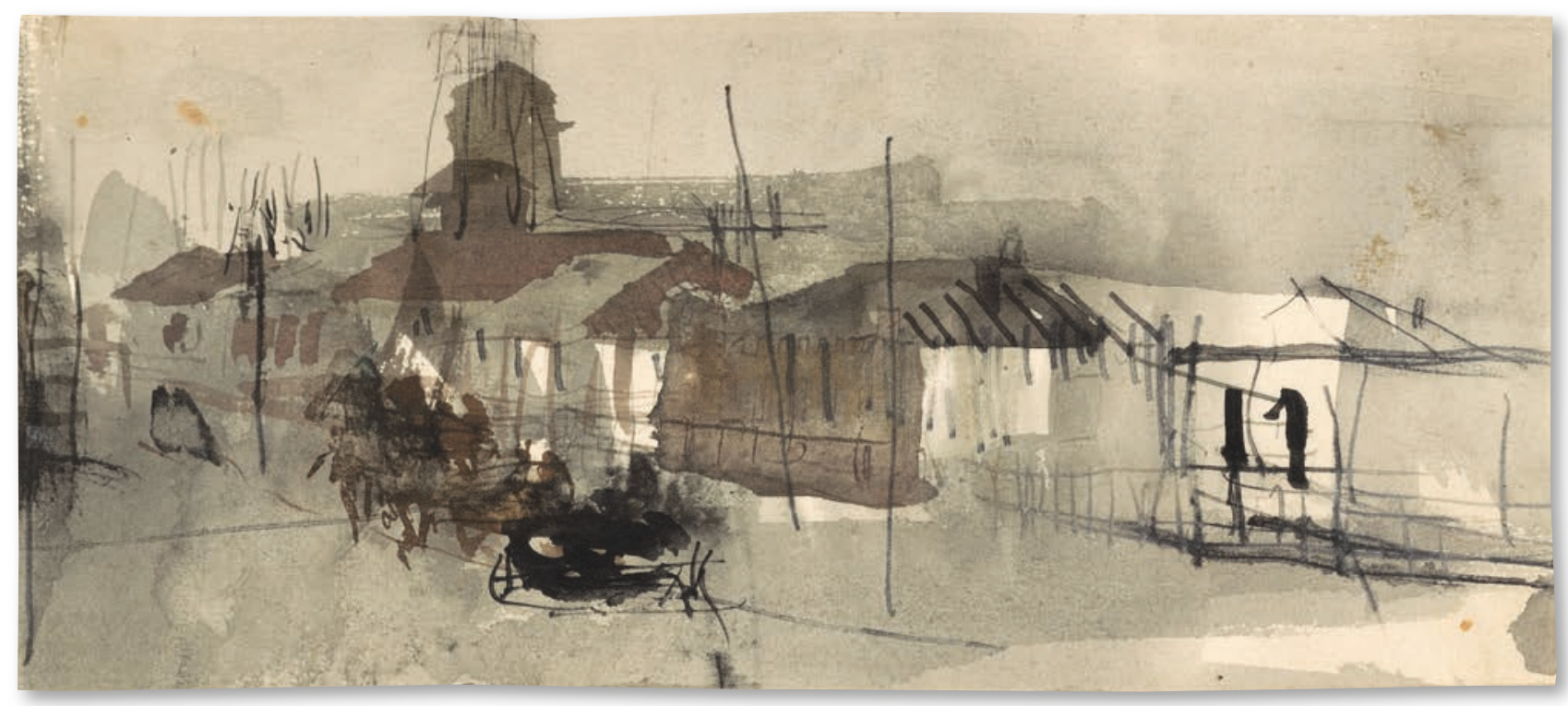

Abb. 1: "Schlitten in russischem Dorf" 1942 / Aquarell / Tuschfeder (B-1, Nr. 6)

Seit März 2018 ist die Landesbibliothek im Besitz des Nachlasses von Walter Brudi (1907-1987). Mit Unterstützung der Stiftung Kulturgut BadenWürttemberg und der Stiftung Würth konnte der Nachlass von Brudis Sohn, Christoph Brudi, erworben werden und stellt mit dem besonderen buchgrafischen Schwerpunkt eine Bereicherung für die Sammlungen der Landesbibliothek dar. Walter Brudi, ein geborener Stuttgarter, studierte hier von 1924 bis 1928 an der Württembergischen Staatlichen Kunstgewerbeschule bei F. H. Ernst Schneidler. Nach seinem Studium war er verantwortlich für das Werbestudio der Firma „Esslinger Wolle". Seine Entwürfe fanden in der Fachwelt solche Anerkennung, dass er bereits 1932 nach Berlin als Leiter der Klasse für Typografie an der Höheren Graphischen Fachschule der Stadt Berlin berufen wurde. Anschließend wechselte er von 1935 bis 1945 an die Meisterschule für Deutschlands Buchdrucker in München. Während des Krieges war er jedoch zwischen 1940 und 1944 als Kriegsmaler in der Ostukraine (damals Sowjetunion) und danach in Frankreich (1944/45) eingesetzt. Die Malereien und Grafiken aus dieser Zeit - vorwiegend bäuerliche russische Szenen und Landschaften in kleineren Formaten - befinden sich in seinem Nachlass (Cod. hist. qt. 824 B). Nachdem er das Kriegsende in einer Kaserne in Wuppertal erlebte und feststellen musste, dass alle höheren Dienstgrade zum Kriegsende verschwanden, desertierte er und konnte zu Fuß nach Stuttgart gelangen.

Von 1949 bis 1973 war er schließlich als Professor an der Staatlichen Akademie der bildenden Künste in Stuttgart tätig: Zunächst war er als Nachfolger von Ernst Schneidler Leiter der Klasse für Buchgraphik und Typographie, von 1966 bis zu seiner Pensionierung gründete und leitete er das Institut für Buchgestaltung. Zehn Jahre lang fungierte er zudem von 1959 bis 1969 als Rektor der Akademie.

Das Nachlassmaterial umfasst im Wesentlichen den künstlerischen Nachlass des Buchgrafikers, Schriftgestalters, Malers und Typografen und spiegelt sein vielseitiges Schaffen auf unterschiedlichen künstlerischen Gebieten wider. Hierzu zählen seine frühen Arbeiten aus der Studienzeit, Malerei und Grafik während des Krieges, freie Malereien und Grafiken, Schutz- und Buchumschläge sowie Schriften für den Rainer-Wunderlich-Verlag; außerdem typografisches Material zu den von inm geschaffenen Schriften Brudi Mediaeval, Brudi Pan und Brudi Orbis, Ausstellungsblätter, Buchdoppelseiten, Verlagsmarken, Signets, aber auch Material zum Thema "Schneidler und seine Zeit" inklusive 


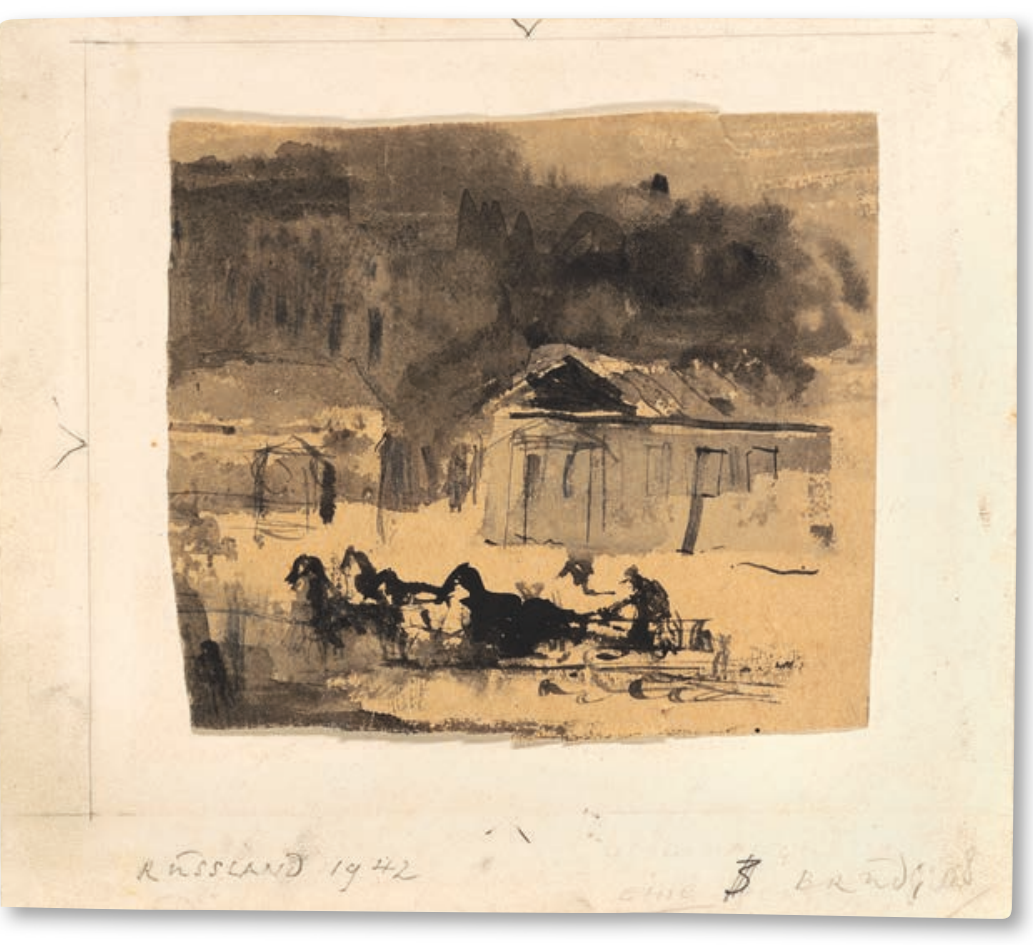

Abb. 2: "Straße in Spola" 1942 / Tusche / Sepia (B-1, Nr. 22)
Briefe von Ernst Schneidler an Brudi. Darüber hinaus beinhaltet er aber auch zahlreiche Korrespondenzen sowohl beruflicher als auch privater Art aus den Jahren 1933 bis 1987 sowie Fotografien. Zu den Briefkonvoluten zählt auch Feldpost der Brüder Walter und Alfred Brudi mit der Familie.

Der Nachlass wurde von der Schwiegertochter Walter Brudis, Heide Brudi, erschlossen. Ein detailliertes Nachlassverzeichnis liegt vor und der Nachlass ist nun unter der Signatur Cod. hist. qt. 824 auf Anfrage bei der Handschriftensammlung benutzbar.

Maria Gramlich

\section{Idyllische Etappe?}

\section{Das Skizzenheft des Stuttgarter Zeichenlehrers Friedrich Gubitz}

Der Erste Weltkrieg war schon zu Ende, als am 23. November 1918 ein "hier herrenlos in einem Wagen von der Front" aufgefundenes Heft vom Militärpostamt Dresden nach Stuttgart verschickt wurde. Glücklicherweise gelangte das Fundstück schließlich wieder zurück in die Familie seines Besitzers. Anfang des Jahres 2018 hat ein Großneffe von Friedrich Gubitz nun das Skizzenheft der Württembergischen Landesbibliothek für die Sammlung "Zeit der Weltkriege" der Bibliothek für Zeitgeschichte übergeben.

Das auf dem Etikett mit "Skizzen aus Nordfrankreich 1915/16" bezeichnete Heft enthält 104 eingeklebte, überwiegend farbige Bleistiftzeichnungen, zwei Tuschzeichnungen und 138 Fotografien. Die meisten Skizzen sind mit Titeln und Datum bezeichnet. Die Fotografien sind weder datiert noch mit Erläuterungen versehen, die abgebildeten Orte ließen sich aber teilweise ermitteln. Etwas rätselhaft bleibt das vermutlich nicht von Gubitz beschriftete Etikett, da auch spätere Skizzen und Ansichten anderer Kriegsgebiete der Westfront im Heft enthalten sind. Die letzte Zeichnung ist datiert auf den 4. September 1918.

Über das Leben von Friedrich Adolf Gubitz (geb. am 13.2.1870) vor dem Ersten Weltkrieg ist bisher nur bekannt, was er selbst während seiner militärischen Ausbildung 1892 in seinen Lebenslauf aufgenommen hat: Der Sohn eines Kanzleirats aus Laupheim war Schüler im Stuttgarter Karlsgymnasium bis zum "Einjährigen" (Schulabschluss), danach ging er in die Lehre bei dem Stuttgarter Hofgraveur und Ziseleur Paul Heckel. Daran anschließend besuchte er die Königliche Kunstgewerbeschule (heute Kunstakademie Stuttgart) und schloss sein Studium mit dem Titel „Diplomzeichenlehrer" ab. In die Personalakten der Württembergischen Armee wird als ziviler Beruf „Kunstmaler und Zeichenlehrer" eingetragen. ${ }^{1}$ 